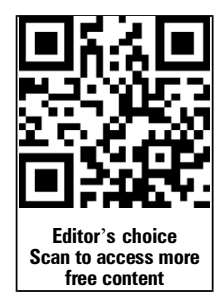

- Additional material is published online only. To view please visit the journal online (http://dx.doi.org/10.1136/ archdischild-2015-309435).

1 Warwick Medical School, University of Warwick Coventry, UK

${ }^{2}$ Department of Economics, University of Warwick, Coventry, UK

${ }^{3}$ Academic Neonatology, UCL Institute for Women's Health, London, UK

${ }^{4}$ Department of Health Sciences, University of Leicester, Leicester, UK ${ }^{5}$ Section of Neonatal Medicine, Department of Medicine, Chelsea and Westminster Campus, Imperial College London, London, UK

Correspondence to Dr S I Watson, Warwick Medical School, University of Warwick, A-155, Warwick Medical School, University of Warwick, Coventry, CV4 7AL, UK;

s.i.watson@warwick.ac.uk

Received 22 July 2015 Revised 6 November 2015 Accepted 12 November 2015 Published Online First 9 February 2016

\section{SLinked}

- http://dx.doi.org/10.1136/ fetalneonatal-2015-310156

\section{CrossMark}

\section{To cite: Watson $\mathrm{SI}$,}

Arulampalam W, Petrou S,

et al. Arch Dis Child Fetal

Neonatal Ed 2016;101:

F195-F200.

\title{
The effects of a one-to-one nurse-to-patient ratio on the mortality rate in neonatal intensive care: a retrospective, longitudinal, population-based study
}

\author{
S I Watson, ${ }^{1}$ W Arulampalam, ${ }^{2}$ S Petrou, ${ }_{1}^{1}$ N Marlow, ${ }_{1}^{3}$ A S Morgan, ${ }^{3}$ ES Draper, ${ }^{4}$ \\ $\mathrm{N}$ Modi, ${ }^{5}$ On behalf of the Neonatal Data Analysis Unit (NDAU) and the Neonatal \\ Economic, Staffing, and Clinical Outcomes Project (NESCOP) Group
}

\begin{abstract}
Objective To estimate the effect of the provision of a one-to-one nurse-to-patient ratio on mortality rates in neonatal intensive care units.

Design A population-based analysis of operational clinical data using an instrumental variable method. Setting National Health Service neonatal units in England contributing data to the National Neonatal Research Database at the Neonatal Data Analysis Unit and participating in the Neonatal Economic, Staffing, and Clinical Outcomes Project.
\end{abstract}

Participants 43 tertiary-level neonatal units observed monthly over the period January 2008 to December 2012.

Intervention Proportion of neonatal intensive care days or proportion of intensive care admissions for which one-to-one nursing was provided.

Outcomes Monthly in-hospital intensive care mortality rate.

Results Over the study period, the provision of one-toone nursing in tertiary neonatal units declined from a median of $9.1 \%$ of intensive care days in 2008 to $5.9 \%$ in 2012. A 10 percentage point decrease in the proportion of intensive care days on which one-to-one nursing was provided was associated with an increase in the in-hospital mortality rate of $0.6(95 \% \mathrm{Cl} 1.2$ to 0.0$)$ deaths per 100 infants receiving neonatal intensive care per month compared with a median monthly mortality rate of 4.5 deaths per 100 infants per month. The results remained robust to sensitivity analyses that varied the estimation sample of units, the choice of instrumental variables, unit classification and the selection of control variables.

Conclusions Our study suggests that decreases in the provision of one-to-one nursing in tertiary-level neonatal intensive care units increase the in-hospital mortality rate.

\section{INTRODUCTION}

Nurse shortages are a continuing problem for healthcare both in the UK and elsewhere. ${ }^{1}{ }^{2}$ Nurse-to-patient ratios have declined in hospitals across many areas of healthcare despite a number of studies providing evidence for an association between increased nurse-to-patient ratios and a reduction in adverse patient clinical outcomes. ${ }^{3-5}$

A one-to-one nurse-to-patient ratio is recommended by the British Association of Perinatal Medicine (BAPM) for all infants receiving neonatal intensive care in the UK, with a ratio of $1: 2$ nurses

\section{What is already known on this topic}

Higher nurse-to-patient ratios in neonatal units are associated with reduced risk of adverse clinical outcomes.

- Many shifts on neonatal units in England are understaffed with respect to recommended nurse-to-patient ratios.

- A one-to-one nurse-to-patient ratio is recommended by the British Association of Perinatal Medicine for infants receiving intensive care.

\section{What this study adds}

- Provision of a one-to-one nurse-to-patient ratio for infants receiving intensive care declined between 2008 and 2012.

- Neonatal units that provided one-to-one nursing on a greater proportion of neonatal intensive care days had a lower mortality rate.

- Provision of a one-to-one nurse-to-patient ratio may be cost-effective for infants receiving intensive care; however, further research is required.

recommended for infants receiving high dependency care and a ratio of 1:4 nurses for infants receiving special care. ${ }^{6} 7$ These levels of care are defined according to the care requirements of the infant, with intensive care requiring the most sustained support. Similar recommendations are provided by the American Academy of Pediatrics. ${ }^{8}$ Despite this, recent evidence shows that a large number of shifts in neonatal units are understaffed with respect to recommended nurse-to-patient ratios. Pillay et $a l^{9}$ found that $54 \%$ of nursing shifts in the six neonatal units they observed in England between October 2008 and February 2009 were understaffed with respect to the 2001 BAPM standards. In 2005, BAPM reported that only $2 \%$ of neonatal intensive care units (NICUs) met national staffing recommendations. ${ }^{10}{ }^{11}$ Understaffing has also been reported in NICUs in the USA. ${ }^{12}$ This evidence has led some groups to advocate increased nurse staffing levels in neonatal units. ${ }^{13}$ 
A recent systematic review ${ }^{4}$ of studies that examined nurse-to-patient ratios in neonatal clinical care settings identified six studies published between 1990 and 2010. ${ }^{14-19}$ As far as we are aware, only two further studies on this topic have been published since that time. ${ }^{12} 20$ The studies included in the systematic review estimated that higher nurse-to-patient ratios are associated with a reduction in risk-adjusted mortality, ${ }^{16} \quad 18 \quad 19$ and of adverse events and nosocomial infection, ${ }^{12} 1520$ and with an increase in daily weight gain. ${ }^{21}$ Of the identified studies, two were from the UK; ${ }^{18} 19$ results from these two studies, however, are based on the same data from 1998 to 1999, prior to wide, systematic changes in the structure of neonatal care in the UK from 2003 onwards. The authors of the systematic review concluded that the included studies were too heterogeneous to support any particular nurse-to-patient ratio. ${ }^{4}$ Moreover, these studies have not been able to observe specific nurse-to-patient ratios at the individual patient level nor adequately account for unobserved confounding that may occur due to higher-risk patients being more likely to receive more intensive nursing support. This in turn has limited the conclusions that can be made regarding the causal effects of the nurse-to-patient ratio on patient clinical outcomes.

This study was designed to estimate the effect of one-to-one nursing on the monthly mortality rate in tertiary-level neonatal units in England. We assess whether tertiary-level neonatal units - those designated to provide intensive care-that provide a greater proportion of intensive care days with one-to-one nursing have lower mortality rates using a novel statistical analysis to account for unobserved confounding.

\section{METHODS}

Data source and study population

Data were extracted from the National Neonatal Research Database (NNRD) for tertiary-level neonatal units participating in the Neonatal, Economic, Staffing, and Clinical Outcomes Project (NESCOP). We used self-reported unit classifications reported to the National Neonatal Audit Programme (NNAP) in 2010 to identify tertiary units. ${ }^{22}$ The NNRD comprises data extracted from the electronic patient records of all infants admitted to all 173 neonatal units in England with units joining the NNRD from 2006 onwards and not all units contributing in all years. NESCOP included 43 tertiary-level centres (of 165 centres overall) providing perinatal care that provided agreement for the inclusion of their data in the NNRD in 2011. NESCOP was able to use data from 30 tertiary units in 2008 (of 146 total units), 34 in 2009 (of 150), 41 in 2010 (of 164), 42 in 2011 (of 165) and 41 in 2012 (of 162). We extracted data on all infants who were admitted to a participating tertiary-level unit over the period 1 January 2008 to 31 December 2012. Two units changed classification during the study period. We, therefore, examined the robustness of our results to these classifications by additionally using unit classifications reported to NNAP in 2008 and 2012.

\section{Outcomes}

The data were aggregated to neonatal unit level by calendar month. Mortality data were derived from the extracted NNRD data. The outcome was specified as the monthly in-hospital intensive care mortality rate and specified as the number of deaths per 100 infants receiving intensive care per month in each neonatal unit.

\section{One-to-one nursing}

The NNRD records a binary variable indicating receipt of one-to-one nursing for each care day provided to each infant.
We validated whether this variable represented whether an infant did receive, as opposed to should have received, one-to-one nursing on the indicated care day, by conducting a number of validation checks. First, we asked staff members at three different neonatal units what information they entered for this variable; second, we compared reported one-to-one nursing provision with clinical guidelines; third, we compared infant risk of mortality with one-to-one provision; and, fourth, we compared one-to-one nursing ratios with average nurse-to-patient ratios using data from a survey of neonatal units participating in NESCOP. The results of these validation checks are presented in online supplementary appendix A. For the analysis at neonatal unit level, the one-to-one nursing variable was specified in two ways: (1) the proportion of intensive care days on which one-to-one nursing was provided and (2) the proportion of infants receiving intensive care who were provided with at least one day of one-to-one nursing. Data were not available on cot numbers or overall staffing levels over the course of the study period.

\section{Covariates}

Following our previous work modelling mortality on neonatal units using NNRD data, and based upon a review of previous prediction models, ${ }^{23}$ we included a number of covariates in our statistical models that (a) were significant predictors of mortality, (b) were available in our data set and of high quality, and (c) not confounded by the provision of neonatal care. These were gestational age at birth, birth weight z-score (birth weight standardised by gestational age week), the monthly neonatal unit volume (to capture nurse workload) and the following indicators: whether the mother received a full or partial course of antenatal steroids, infant sex, infant year of birth (to capture trends in mortality over time) and calendar month (to capture any seasonal trends in mortality). In addition, a neonatal unit indicator (fixed effect) was included (see online supplementary appendix B).

\section{Statistical methods}

One-to-one nursing is assigned only to the sickest infants receiving neonatal intensive care, who will have the highest risk of mortality. This will generally lead us to underestimate the benefit or even to predict an adverse effect of one-to-one nursing due to the effect of unobserved confounding if infant health is not perfectly observed. We aggregated data to unit level for each calendar month in the sample so that unobserved heterogeneity at the infant level was not a confounding factor. A neonatal unit-level model was also arguably appropriate to inform neonatal unit-level policy. Nonetheless, there are two issues that may affect the analyses: (1) unobserved confounding at neonatal unit level and (2) reverse causality from the risk of mortality to one-to-one nursing due to the increased provision of intensive nursing to sicker infants (ie, ill health causing one-to-one provision).

A linear regression model was specified with controls for unobserved characteristics (unit fixed effects) to account for the neonatal unit-level unobserved confounding. The model was then estimated using ordinary least squares (OLS). To account for reverse causality, we used an instrumental variables estimator. This instrumental variables estimator involves the use of a variable, termed an 'instrument' that in this context fulfils two criteria: (1) it should be strongly correlated with the one-to-one nursing ratio in a particular month and (2) it should not be correlated with the outcome of interest conditional on observed covariates, including one-to-one nursing. For the instruments, 
we used lagged values of the one-to-one nursing ratio (ie, previous months' values for one-to-one nursing ratios for the respective neonatal unit) since (1) a particular month's one-to-one nursing ratio should be correlated with previous monthly ratios at a unit level given the availability of nursing staff and local nursing practices and (2) the previous monthly ratios should be uncorrelated with unobserved confounders during the month of analysis. The number of lagged values included was determined by sequential testing (see online supplementary appendix B). To test the first condition, we conducted an F-test for the significance of the lagged values, and to test the second condition we conducted a Hansen J test. ${ }^{24}$ The SEs were adjusted for clustering within units. Analyses were conducted in Stata V.12.

\section{Sensitivity analyses}

A number of sensitivity analyses were conducted to determine the robustness of the results to the statistical methods, the set of included covariates and assumptions of the models. In particular, we tested the sensitivity of our results to (1) including only neonatal units that provided data for all months of the analysis; (2) exclusion of any outlying units identified from a graphical inspection of the data; (3) inclusion of non-tertiary units that provide an average monthly level of intensive care at least as large as the smallest tertiary unit; (4) re-estimating the models with no covariates, except for unit-level indicators and the one-to-one nursing variable; (5) using a different number of lagged values for the instruments; (6) using 2008 and 2012 reported unit classifications; and (7) removing data from 2008 when large decreases in one-to-one nursing were observed that were not observed in subsequent years.

\section{RESULTS}

\section{Summary statistics}

Overall, data from 43 unique tertiary neonatal units were included in our primary analyses. Of the remaining 122 neonatal units in NESCOP, 82 reported as being level 2 and 40 as level 1 in $2010 .^{6}$ Table 1 shows summary statistics for the sample; the top panel shows sample aggregate statistics, while the lower panel shows neonatal unit median values. The median annual proportion of intensive care days on which one-to-one nursing was provided in tertiary neonatal units in the sample declined from $9.1 \%$ in 2008 to $5.9 \%$ in 2012. Similarly, the proportion of infants admitted to intensive care receiving any one-to-one nursing during their care declined from $39.4 \%$ to $35.7 \%$ over the same period. The median (IQR) in-hospital intensive care mortality rate was 4.5 (0.0 to 8.3) deaths per 100 infants receiving intensive care per month.

\section{Regression results}

Estimated effects of one-to-one nursing on the in-hospital intensive care mortality rate are reported in table 2 for both OLS and the instrumental variables estimator. The OLS results revealed a positive association between the one-to-one nursing ratio and the in-hospital intensive care mortality rate, suggesting that a 10 percentage point decrease in the proportion of intensive care days on which one-to-one nursing was provided was associated with a decrease in the mortality rate of 0.6 deaths per 100 infants receiving intensive care per month (95\% CI 0.1 to 1.2 ).

After adjusting for possible reverse causality, the instrumental variables estimator results showed strong evidence of an increase in the mortality rate was associated with a higher one-to-one nursing ratio. A 10 percentage point decrease in the proportion of intensive care days on which one-to-one nursing was provided was associated with an increase in the mortality rate of
0.6 deaths per 100 infants receiving neonatal intensive care per month $(95 \% \mathrm{CI}-1.2$ to -0.0$)$. Where one-to-one nursing was measured as the proportion of infants who received at least one day of one-to-one nursing care, a 10 percentage point decrease in one-to-one nursing led to an increase of 0.4 deaths per 100 infants receiving neonatal intensive care per month $(95 \% \mathrm{CI}$ -0.7 to -0.0$)$.

\section{Sensitivity analyses}

The results from the sensitivity analyses are presented in online supplementary appendix C, tables C1-C4. In all cases, the estimated coefficients were negative and were qualitatively similar to the main results. Removal of neonatal units that did not contribute data in all months of the analysis and removal of one outlying unit generally resulted in an increase in the magnitude of the estimated coefficients while reducing precision of the estimates (see online supplementary tables C1 and C3). Varying the lag length of the instrumental variables used had small effects on the magnitude of the estimated coefficients of interest and SEs as was expected (see online supplementary tables C2 and C4). For one-to-one nursing measured as a proportion of intensive care days, the inclusion of extra lagged months as instrumental variables had little qualitative effect on the estimated coefficient, while reducing the number of lagged months reduced the magnitude of the coefficient. For one-to-one nursing measured as a proportion of admissions, the inclusion of extra lagged months increased the magnitude of the estimated coefficient, while reducing the number of lagged months had little qualitative effect on the estimated coefficient. The choice of lag length used as instrumental variables, therefore, affects the point estimates of the effect of one-to-one nursing, suggesting there is a fair amount of uncertainty about the effects of one-to-one nursing on the mortality rate; however, these changes did not affect the general conclusions drawn from the results that an increase in the provision of one-to-one nursing was associated with a reduction in the mortality rate. Variations in reported unit classifications over the study period did not affect the results. Removal of data from 2008, given the trend observed in this period, did not affect the magnitude of the estimate but did reduce its precision.

\section{DISCUSSION}

We examined the effect of one-to-one nursing in neonatal intensive care on the monthly mortality rate in NICUs for infants admitted to neonatal units in England. The key finding was an increase in the mortality rate in tertiary-level neonatal units when a decreased proportion of intensive care days was provided with one-to-one nursing. The results from the OLS results showed the opposite effect, which provides evidence that sicker infants were more likely to be provided with one-to-one nursing, thereby confounding the standard analysis. The results from analyses where an alternative measure of one-to-one nursing, along with the results from a wide variety of robustness checks, were all qualitatively similar, supporting the main instrumental variables estimator findings.

The methods used in this study enabled us to account for a number of sources of unobserved confounding so that our results can be arguably interpreted as causal effects in the absence of a randomly assigned one-to-one nurse-to-patient ratio. This study employed an instrumental variable method, which has been widely applied in other healthcare evaluations. ${ }^{25}$ However, we are only aware of two previous studies incorporating this method in perinatal settings, including one study using NNRD data previously conducted by the authors. ${ }^{26} 27$ Our 
Table 1 Characteristics of tertiary neonatal units in the sample

\begin{tabular}{|c|c|c|c|c|c|}
\hline Variable & 2008 & 2009 & 2010 & 2011 & 2012 \\
\hline $\begin{array}{l}\text { Number of unique neonatal units contributing data to } \\
\text { primary sample }\end{array}$ & 30 & 34 & 41 & 42 & 41 \\
\hline \multicolumn{6}{|l|}{ Summary statistics for whole sample } \\
\hline Total intensive care days & 63036 & 70256 & 75400 & 89893 & 97681 \\
\hline Total one-to-one care days & 9415 & 6086 & 6085 & 7080 & 7474 \\
\hline $\begin{array}{l}\text { Percentage of intensive care days on which } \\
\text { one-to-one nursing was provided }\end{array}$ & 14.9 & 8.7 & 8.1 & 7.9 & 7.7 \\
\hline $\begin{array}{l}\text { Percentage of infants receiving intensive care } \\
\text { and at least one day of one-to-one nursing }\end{array}$ & 38.4 & 38.6 & 37.0 & 37.6 & 36.4 \\
\hline Monthly intensive care mortality rate (\%) & 4.5 & 4.9 & 6.5 & 6.0 & 5.4 \\
\hline \multicolumn{6}{|c|}{ Monthly median (IQR) values of neonatal units in the sample reported by year } \\
\hline Monthly intensive care days provided & $181(121.5$ to 235.5$)$ & 176 (122 to 237) & $151.5(100.2$ to 233.5$)$ & 159 (114 to 249) & 178.5 (120 to 272.2$)$ \\
\hline Monthly one-to-one care days provided & 13 (6 to 30$)$ & 9 (4 to 20$)$ & 10 (4 to 18$)$ & 11 (5 to 19$)$ & 11 (5 to 21$)$ \\
\hline $\begin{array}{l}\text { Percentage of intensive care days on which } \\
\text { one-to-one nursing was provided }\end{array}$ & 9.1 (3.8 to 17.5$)$ & $6.1(2.6$ to 11.7$)$ & $6.2(3.2$ to 11.8$)$ & $6.5(3.4$ to 11.2$)$ & 5.9 (3.1 to 10.8$)$ \\
\hline $\begin{array}{l}\text { Percentage of infants receiving intensive care } \\
\text { and at least one day of one-to-one nursing }\end{array}$ & $39.4(25.4$ to 55.0$)$ & $\begin{array}{l}37.5(26.1 \text { to } \\
50.0)\end{array}$ & $36.8(25.0$ to 50.0$)$ & $\begin{array}{l}37.5(25.0 \text { to } \\
50.0)\end{array}$ & 35.7 (25.0 to 47.1$)$ \\
\hline Monthly intensive care mortality rate (\%) & $4.0(0.0$ to 7.7$)$ & $4.4(0.0$ to 7.7$)$ & $5.3(0.0$ to 9.1$)$ & $5.3(0.0$ to 9.5$)$ & $4.5(0.0$ to 8.3$)$ \\
\hline
\end{tabular}

findings can be compared with three previously conducted studies that found a reduction in risk-adjusted mortality with higher nurse-to-patient ratios in neonatal healthcare. ${ }^{14} 1819$ One previous study did find an increase in mortality. ${ }^{14}$ However, none of the cited earlier studies took into account the various sources of unobserved confounding and the possibility of reverse causality, and all examined the effects of an average nurse-to-patient ratio in cross-sectional contexts at the baby level without being able to examine within-unit changes to nurse-to-patient ratios over time. The difference between our OLS and instrumental variables estimator results suggest that there is significant reverse causality from one-to-one nursing to mortality, which may be caused by unobservable differences in patient case mix or by differences or changes over time to the technology in use by neonatal units.

The results presented in this study could serve as inputs into models that estimate the incremental cost per life saved associated with increased provision of one-to-one nursing. As an illustrative example of this, consider the case of a hospital providing 180 intensive care days per month. If it is assumed that infants who receive intensive care at a ratio of $2: 1$ rather than $1: 1$, then an increase in the one-to-one nursing rate of 10 percentage points requires an additional nine days of nursing labour, which would have the effect of reducing the mortality rate by 0.6 percentage points, equivalent to 1.08 deaths. The unit costs for an hour of face-to-face specialist nursing was estimated at $£ 64$ in $2014 .^{28}$ This would result in an incremental cost of $£ 12800$ per life saved, which would generally be considered cost-effective by decision-making bodies such as the National Institute for Health and Care Excellence in England and Wales. ${ }^{29}$ We recognise that this calculation is illustrative rather than proscriptive, and further research is required to incorporate considerations of staff position, qualifications, experience and other factors.

We acknowledge limitations to our study. Our study is only able to identify the 'marginal' effects of the one-to-one nursing ratio on the in-hospital intensive care mortality rate; the effects of large increases in one-to-one nursing provision remain unknown. Even with $100 \%$ one-to-one nursing provision to infants during neonatal intensive care, the mortality rate will not be zero. Thus, while these findings support an increase in one-to-one nursing provision on tertiary-level neonatal units, they do not inform us whether a one-to-one nurse-to-patient ratio for all intensive care days would have a beneficial effect. We are, furthermore, not able to identify the optimal nurse-to-patient ratio given that we only observe whether an infant received one-to-one nursing or not; for example, it is possible that a greater than one-to-one nurse-to-patient ratio has additional beneficial effects. Further research is required to determine the optimal levels of nurse staffing to best improve infant clinical outcomes. This would involve infant-level, daily observations of nursing support for infants receiving care in a neonatal unit.

One further weakness of our study is that we are not able to determine whether nurses should be reallocated from other nursing tasks in neonatal units to one-to-one nursing in neonatal intensive care. Time-use studies were conducted in the early 1990 s to determine nurse-to-patient ratios recommended by BAPM. $^{30}{ }^{31}$ A more recent study reaffirmed these results and suggested required nursing time had increased. ${ }^{32}$ New time-use studies are, therefore, an important area for future research.

Our study is also not able to suggest when during an infants' care one-to-one nursing would achieve its optimal effects. Increasing one-to-one nursing provision is assumed to reduce preventable nursing errors that may lead to mortality. In the first hours of life, this effect may be small as the underlying medical condition may have a larger effect. Many errors may not be prevented by increasing the nurse-to-patient ratio but through other quality improvements. We have assumed that increases in the provision of one-to-one nurses are indicative of increases in the overall nurse-to-patient ratio. Nevertheless, we have provided evidence that increases in one-to-one nursing provision for neonatal intensive care lead to a reduction in mortality. Further research is required both to establish how this is achieved in practice and to find other quality improvements that may reduce mortality. We also note that given the complexities 
Table 2 Estimated effect of an increase in the provision of one-to-one nursing on the mortality rate

One-to-one nursing measured as a proportion of intensive care days*

Estimated effect of a 10 percentage point increase in 0.6 one-to-one nursing on the monthly mortality rate (deaths per 100 infants receiving intensive care per month)

$95 \% \mathrm{Cl}$

$p$ Value 0.1 to 1.2

Number of unique neonatal units 0.05

Total observations

43

2228

Instrumental variables estimator

Estimated effect of a 10 percentage point increase in $-0.6$ one-to-one nursing on the monthly mortality rate (deaths per 100 infants receiving intensive care per month)

$95 \% \mathrm{Cl}$

-1.2 to -0.0

$p$ Value

0.04

Number of unique neonatal units

43

Total number of observations 2140

One-to-one nursing measured as a proportion of admissionst

Estimated effect of a 10 percentage point increase in one-to-one nursing on the monthly mortality rate (deaths per 100 infants receiving intensive care per month)

$95 \% \mathrm{Cl}$

$p$ Value

0.1 to 0.6

Number of unique neonatal units

Total observations

0.002

43

2228

Instrumental variables estimator

Estimated effect of a 10 percentage point increase in $-0.4$

one-to-one nursing on the monthly mortality rate

(deaths per 100 infants receiving intensive care per month)
$95 \% \mathrm{Cl}$

-0.7 to -0.0

0.03

43

Number of unique neonatal units

2140

Total number of observations
Results are presented from two different estimators: (1) ordinary least squares, which does not control for the correlation between the one-to-one nursing and unobserved case-mix differences; (2) instrumental variables estimator, which does control for the correlation between the one-to-one nursing and unobserved case-mix differences using historical nursing levels. Results are interpreted as change in the number of deaths per 100 infants receiving neonatal intensive care per month resulting from a 10 percentage point increase in one-to-one nursing.

Regressions control for the mean values of gestational age, birth weight z-score, antenatal steroid receipt and gender, as well as year, calendar month and neonatal unit effects (see online supplementary appendix B). The number of observations are fewer for the instrumental variables estimation as lagged variables are used as instruments. Sensitivity analyses are presented in online supplementary appendix C. ${ }^{*}$ The proportion of intensive care days on which a one-to-one nurse to patient ratio was provided.

tThe proportion of intensive care admissions who received at least one day of care on which one-to-one nursing was provided.

involved in neonatal care and potentially large differences in practice between countries, these results may not be generalisable to other countries or healthcare systems.

This study provides evidence to support the claim that tertiary-level neonatal units with higher levels of one-to-one nursing provision have reduced mortality rates. Further research is clearly warranted on the best way to achieve this. Furthermore, the benefits of increasing the nurse-to-patient ratio may be underestimated in this study since common neonatal morbidities are not considered, and previous studies have shown an increased nurse-to-patient ratio is associated with a reduction in the risk of diseases such as infection, bronchopulmonary dysplasia and intraventricular haemorrhage. ${ }^{15} 1621$ This would be an important extension to these analyses in future. We believe the results in this study provide some evidence in support of a one-to-one nurse-to-patient ratio in neonatal intensive care in England, in line with BAPM guidelines, and therefore provide evidence in support of increased nursing labour provision on neonatal units in England.

Twitter Follow Samuel Watson at @siwatson

Acknowledgements We thank Nicola Fitz-Simon for invaluable advice on statistical issues and Shalini Santhakumaran, Eugene Statnikov and Daniel Gray for assistance with the data. We thank the staff from neonatal units involved in capturing electronic data and Richard Colquhoun, Neonatal Data Analysis Unit manager and Surbhi Shah for administrative support. We would also like to thank Andy Cole, Kate Bennett, Helen Kirrane and the Steering Board of the Neonatal Data Analysis Unit. We additionally thank Matt Sutton and Anne Spencer for their useful comments and guidance. We would also like to thank the following contributing neonatal units and clinical leads (all units were included in the NESCOP survey and offered an 'opt out' of service evaluation that made use of NNRD data): Matthew Babirecki, Airedale General Hospital; Andrew Gallagher, Alexandra Hospital; D Manning, Arrowe Park Hospital; Tim Wickham, Barnet Hospital; MA Saeed, Barnsley District General Hospital; Nawfal Sharief, Basildon Hospital; Ruth Wigfield, Basingstoke \& North Hampshire Hospital; Nigel Brooke, Bassetlaw District General Hospital; Raghavan Kadalraja, Bedford Hospital; Julie Nycyk, Birmingham City Hospital; Mike Watkinson, Birmingham Heartlands Hospital; Imogen Morgan, Birmingham Women's Hospital; Sam Oddie, Bradford Royal Infirmary; R.N Mahesh Babu, Broomfield Hospital; Eleri Crosbie, Calderdale Royal Hospital; Tim Wickham, Chase Farm Hospital; Gary Hartnoll, Chelsea \& Westminster Hospital; Aiwyne Foo, Chesterfield Royal Hospital; Sarah Dalton,Colchester General Hospital; Graham Whincup, Conquest Hospital; Stephen Brearey, Countess of Chester Hospital; John Chang, Croydon University Hospital (Mayday); Mahfud Ben-Hamida, Cumberland Infirmary; Abdul Hasib, Darent Valley Hospital; S Subramania Krish Namoorthy, Darlington Memorial Hospital; Julian Larson, Derriford Hospital; Kallinath Shyamannr, Dewsbury \& District Hospital; Pauline Adiotomre, Diana Princess of Wales Hospital; Nigel Brooke, Doncaster Royal Infirmary; Phil Wylie, Dorset County Hospital; Vivien Chan, Ealing Hospital; K Aboul Khader, East Surrey Hospital; Graham Whincup, Eastbourne District General Hospital; Ruth Shephard, Epsom General Hospital; Sri Nagesh Panasa, Fairfield general; JP Wyllie, Friarage Hospital; Abdus Mallik, Frimley Park Hospital; Owen Galt, Furness General Hospital; R C de Boer, George Eliot Hospital; Jennifer Holman, Gloucestershire Royal Hospital; Mike Watkinson, Good Hope Hospital; Stanley Zengeya, Great Western Hospital; Morag Campbell, Guy's \& St Thomas' Hospital; D Gillies, Harrogate District Hospital; Andrew Butterfill, Hereford County Hospital; Michele Cruwys, Hillingdon Hospital; Hilary Dixon, Hinchingbrooke Hospital; Kate Costeloe, Homerton Hospital; Eleri Adams, Horton Hospital; Chris Wood, Hull Royal Infirmary; Matthew James, Ipswich Hospital; JP Wyllie, James Cook University Hospital; Vasantha Jayalal, James Paget Hospital; Eleri Adams, John Radcliffe Hospital; Pratibha Rao, Kettering General Hospital; B K Sharma, King George Hospital; Abhi Gkeenga, King's College Hospital; Vibert Noble, King's Mill Hospital; Dwight Lindo, Kingston Hospital; Meera Lama, Lancashire Women and Newborn Centre; Lawrence Miall, Leeds Neonatal Service; Andrew Currie, Leicester General Hospital; Andrew Currie, Leicester Royal Infirmary; A Thirumurugan,L eighton Hospital; Sudhakar Rao, Lincoln County Hospital; Andy Raffles, Lister Hospital; CW Yoxall, Liverpool Women's Hospital; P Sivakumar, Luton \& Dunstable Hospital; Ignatios Losa, Macclesfield District General Hospital; Hamudi Kisat, Maidstone; B Jan Muhamad, Manor Hospital; Aung Soe, Medway Maritime Hospital; Jasper Katumba, Milton Keynes Foundation Trust Hospital; Babu Kumararatne, New Cross Hospital; Vimala Gopinathan, Newham General Hospital; Mark Dyke, Norfolk \& Norwich University Hospital; Yonas Cherinet ,North Devon District Hospital; Sri Nagesh Panasa, North Manchester General Hospital; Lesley Alsford, North Middlesex University Hospital; Fiona Thompson, Northampton General Hospital; Paul Mannx, Northwick Park Hospital; Stephen Wardle, Nottingham City Hospital; Stephen Wardle, Nottingham University Hospital; Tim McBride, Ormskirk District General Hospital; Seif Babiker, Peterborough City Hospital; Sudhakar Rao, Pilgrim Hospital; Minesh Khashu, Poole Hospital NHS Foundation Trust; Than Soe, Princess Alexandra Hospital; Mike Hall, Princess Anne Hospital; Philip Amess, Princess Royal Hospital; Shaun Walter, Princess Royal University Hospital; Andy Raffles, Queen Elizabeth II Hospital; CR Groves, Queen Alexandra Hospital; Lidia Tyszczuk, Queen Charlotte's Hospital; Susan Rubin, Queen Elizabeth Hospital; Shaun Walter, Queen Elizabeth Hospital; Dennis Bosman, Queen Elizabeth Hospital (Gateshead); David Long, Queen Elizabeth the Queen Mother Hospital; Azhar Manzoor, Queen's Hospital; B K Sharma, Queen's Hospital; Amanda Ogilvy-Stuart, Rosie Maternity Hospital; Christine Harrison, Rotherham District General Hospital; 
Vibha Sharma, Royal Albert Edward Infirmary; GJ Boson, Royal Berkshire Hospital; M Yadan, Royal Bolton Hospital; Paul Munyard, Royal Cornwall Hospital; John McIntyre, Royal Derby Hospital; Vaughan Lewis, Royal Devon \& Exeter Hospital; D Schapira, Royal Hampshire County Hospital; Owen Galt, Royal Lancaster Infirmary; Natasha Maddock, Royal Oldham Hospital; Richa Gupta, Royal Preston Hospital; Alison Moore, Royal Shrewsbury Hospital; Charles Godden, Royal Surrey County Hospital; Philip Amess, Royal Sussex County Hospital; Steve Jones, Royal United Hospital; Alan Fenton, Royal Victoria Infirmary; Anande Mohite, Russells Hall Hospital; Jonathan Moise, Salford Royal; Shirley Kinsey, Salisbury District Hospital; Mazen Qunibi, Scarborough General Hospital; Pauline Adiotomre, Scunthorpe General Hospital; Rob Bolton, South Tyneside District Hospital; Arfa Khan, Southend Hospital; Richard Wach, Southmead Hospital; Sandra Calvert, St George's Hospital; Ruth Shephard, St Helier Hospital; Anthony Emmerson, St Mary's Hospital; Peter Chow, St Mary's Hospital; Sian Butterworth, St Mary's Hospital; James Tooley, St Michael's Hospital; Peter Reynolds, St Peter's Hospital; Avril Garg, St Richard's Hospital; KK Tewary, Staffordshire General Hospital; Carrie Heal, Stepping Hill Hospital; Gail Whitehead, Stoke Mandeville Hospital; Majd Abu-Hard, Sunderland Royal Hospital; Jacqueline Birch, Tameside General Hospital; Rebecca Mann, Taunton \& Somerset Hospital; Elizabeth Pilling, The Jessop Wing; Vivienne van Someren, The Royal Free Hospital; Rainer Ebel, The Royal London Hospital; Stefan Schulee, Torbay Hospital; Hamudi Kisat, Tunbridge Wells Hospital; Mark Sellwood, University College Hospital; Kate Blake, University Hospital Coventry; Jauro Kuna, University Hospital Lewisham; S Subramania Krish Namoorthy, University Hospital of North Durham; Kate Palmer, University Hospital of North Staffordshire; lan Verber, University Hospital of North Tees; Faisal Al-Zidgali, University Hospital of South Manchester; AJ Rowlands, Victoria Hospital; Joan Oliver, Wansbeck General Hospital; Delyth Webb, Warrington Hospital; R B Acharya, Warwick Hospital; Chaniyil A Ramesh,Watford General Hospital; Mahfud Ben-Hamida, West Cumberland Hospital; Hashir Ariff, West Middlesex University Hospital; lan Evans, West Suffolk Hospital; Rekha Sanghavi, Wexham Park Hospital; Caroline Sullivan, Whipps Cross University Hospital; Laweh Amegavie, Whiston Hospital; ER Broadhurd, Whittington Hospital; David Long, William Harvey Hospital; Andrew Gallagher, Worcestershire Royal Hospital; Anil Garg, Worthing Hospital; Megan Eaton, Yeovil District Hospital; Guy Millman, York District Hospital.

Contributors SIW conceived the study. SIW, WA and SP contributed to developing the statistical methodology for the study. SIW prepared the data for analysis. SIW, WA, SP, NMa, ASM, ESD and NMo contributed to covariate selection and interpretation of the results. SIW prepared the first draft of the paper. This and all subsequent drafts were reviewed and revised by all authors. All authors approved the final version submitted.

Funding The Neonatal Data Analysis Unit is supported in part by a Programme Grant for Applied Research (RP-PG-0707-10010) from the National Institute of Health Research (NIHR) and has previously received funding from the Department of Health and unrestricted funding from Danone, AbbVie and Abbott International. SW received funding from Bliss and the Department of Economics, University of Warwick. Bliss also provided funding for the NESCOP group. NMa receives part funding from the Department of Health's NIHR Biomedical Research Centre's funding scheme at UCLH/UCL.

Disclaimer The study funders had no role in study design, collection, analysis, and interpretation of data, writing of the report, or in the decision to submit the article for publication.

Competing interests None declared.

Ethics approval This study was carried out with the National Neonatal Research Database (REC 10/H0803/151) as part of NESCOP undertaken with permission from NHS Trust Caldicott Guardians.

Provenance and peer review Not commissioned; externally peer reviewed.

\section{REFERENCES}

1 Buchan J, Aiken L. Solving nursing shortages: a common priority. J Clin Nurs 2008; 17:3262-8

2 Buchan J, Seccombe I. Overstretched. Under-resourced. The UK nursing labour market review 2012. 2012. http://eresearch.qmu.ac.uk/3127/1/eResearch_3127.pdf

3 Kane RL, Shamliyan TA, Mueller C, et al. The association of registered nurse staffing levels and patient outcomes: systematic review and meta-analysis. Med Care 2007;45:1195-204.

4 Sherenian M, Profit J, Schmidt B, et al. Nurse-to-patient ratios and neonatal outcomes: a brief systematic review. Neonatology 2013;104:179-83.

5 Needleman J, Buerhaus P, Pankratz VS, et al. Nurse staffing and inpatient hospital mortality. N Engl J Med 2011;364:1037-45.
6 British Association of Perinatal Medicine. Categories of Care 2011. Categ. Care 2011. 2011. http://www.bapm.org/publications/documents/guidelines/ CatsofcarereportAug 11.pdf (accessed 12 Jun 2012).

7 British Association of Perinatal Medicine. Standards for Hospitals Providing Neonatal Intensive Care and High Dependency Care. London 2001.

8 American Academy of Pediatrics Committee on Fetus and Newborn, American College of Obstetricians and Gynecologists Committee on Obstetric Practice. Guidelines for Perinatal Care. 7th Editio. 2012.

9 Pillay T, Nightingale P, Owen S, et al. Neonatal nursing efficacy: practical standards of nursing care provision in a newborn network. Arch Dis Child 2011;96:A36.

10 Redshaw ME, Hamilton K. A Survey of current neonatal unit organisation and policy. National Perinatal Epidemiology Unit, University of Oxford, Oxford, UK, 2005.

11 Tucker J, Tarnow-Mordi W, Gould C, et al. UK neonatal intensive care services in 1996. On behalf of the UK Neonatal Staffing Study Collaborative Group. Arch Dis Child Fetal Neonatal Ed 1999;80:F233-4.

12 Rogowski JA, Staiger D, Patrick T, et al. Nurse staffing and NICU infection rates. JAMA Pediatr 2013;167:444-50.

13 Bliss. SOS: Save our special care babies. Save our specialist nurses. London, 2011 http://www.bliss.org.uk/wp-content/uploads/2012/02/SOS_report_aw-lo-res.pdf

14 Callaghan LA, Cartwright DW, O'Rourke P, et al. Infant to staff ratios and risk of mortality in very low birthweight infants. Arch Dis Child Fetal Neonatal Ed 2003;88: F94-7.

15 Cimiotti JP, Haas J, Saiman L, et al. Impact of staffing on bloodstream infections in the neonatal intensive care unit. Arch Pediatr Adolesc Med 2006;160:832-6.

16 Grandi C, González A, Meritano J. [Patient volume, medical and nursing staffing and its relationship with risk-adjusted outcomes of VLBW infants in 15 Neocosur neonatal network NICUs]. Arch Argent Pediatr 2010;108:499-510.

17 Profit J, Zupancic JAF, McCormick MC, et al. Moderately premature infants at Kaiser Permanente Medical Care Program in California are discharged home earlier than their peers in Massachusetts and the United Kingdom. Arch Dis Child Fetal Neonatal Ed 2006;91:F245-50.

18 Hamilton KESC, Redshaw ME, Tarnow-Mordi W. Nurse staffing in relation to risk-adjusted mortality in neonatal care. Arch Dis Child Fetal Neonatal Ed 2007;92: F99-103.

19 Tucker J. Patient volume, staffing, and workload in relation to risk-adjusted outcomes in a random stratified sample of UK neonatal intensive care units: a prospective evaluation. Lancet 2002;359:99-107.

20 Lamy Filho F, da Silva AAM, Lopes JMA, et al. Staff workload and adverse events during mechanical ventilation in neonatal intensive care units. J Pediatr (Rio J) 2011;87:487-92.

21 Profit J, Petersen LA, McCormick MC, et al. Patient-to-nurse ratios and outcomes of moderately preterm infants. Pediatrics 2010;125:320-6.

22 Royal College of Pediatrics and Child Health. NNAP Annual Report 2010. London, 2011.

23 Medlock S, Ravelli ACJ, Tamminga P, et al. Prediction of mortality in very premature infants: a systematic review of prediction models. PLOS ONE 2011;6: e23441.

24 Godfrey L. Misspecifications tests in econometrics. 1st edn. Cambridge: Cambridge University Press, 1988.

25 Tsai AC, Votruba M, Bridges JFP, et al. Overcoming bias in estimating the volume-outcome relationship. Health Serv Res 2006;41:252-64.

26 Lorch SA, Baiocchi M, Ahlberg CE, et al. The differential impact of delivery hospital on the outcomes of premature infants. Pediatrics 2012;130:270-8.

27 Watson SI, Arulampalam W, Petrou S, et al. The effects of designation and volume of neonatal care on mortality and morbidity outcomes of very preterm infants in England: retrospective population-based cohort study. BMJ Open 2014;4: e004856-e004856.

28 Curtis L. Unit Costs of Health \& Social Care 2014. Canterbury, 2014. http://www. pssru.ac.uk/project-pages/unit-costs/2014/index.php

29 National Institute for Health and Care Excellence. Guide to the methods of technology appraisal 2013. London, 2013. http://publications.nice.org.uk/ guide-to-the-methods-of-technology-appraisal-2013-pmg9

30 Northern Neonatal Network. Measuring neonatal nursing workload. Northern Neonatal Network. Arch Dis Child 1993;68:539-43.

31 Williams $S$, Whelan $A$, Weindling $A M$, et al. Nursing staff requirements for neonatal intensive care. Arch Dis Child 1993;68:534-8.

32 Milligan DWA, Carruthers P, Mackley B, et al. Nursing workload in UK tertiary neonatal units. Arch Dis Child 2008;93:1059-64. 